\title{
MULTITEMPORAL SPECTRAL ANALYSIS FOR ALGAE DETECTION IN AN EUTROPHIC LAKE USING SENTINEL 2 IMAGES
}

\author{
German Alba $^{1, *}$, Ferral Anabella ${ }^{1}$, Scavuzzo Carlos Marcelo ${ }^{1}$, Shimoni Michal ${ }^{2}$ \\ ${ }^{1}$ Mario Gulich Institute, CONAE-UNC, Córdoba, Argentina. \\ ${ }^{2}$ Signal and Image Center, Belgian Royal Military Academy (SIC-RMA), Brussels, Belgium.
}

KEY WORDS: Eutrophication, phytoplankton, Sentinel-2, multitemporal, unmixing, turbid water

\begin{abstract}
:
Eutrophication is characterized by excessive plant and algal growth due to the increased of organic matter, carbon dioxide and nutrients in water body. Although eutrophication naturally occurs over centuries as lakes age, human activities have accelerated it processes and caused dramatic changes to the aquatic ecosystems including elevated algae blooms and risk for hypoxia as well as degradation in the quality of drinking water and fisheries. Monitoring eutrophic processes is therefore highly important to human health and to the aquatic environment. However, the spatial and seasonal distribution of the phenomena and its dynamic are difficult to be resolved using conventional methods as water sampling or sparse acquisition of remote sensing data. This research work proposes a methodology that takes advantage of the high temporal resolution of Sentinel-2 (S2) for monitoring eutrophic reservoir. Specifically, it uses large temporal series of S2 images and advanced temporal unmixing model to estimate the abundance of [Chla] and algae species in San Roque reservoir, Argentina, in the period August 2016 to August 2019. The spatial patterns and the temporal tendencies of these aquatic indicators, that have a direct link to Eutrophication, were analysed and evaluated using in situ data in order to assess their contribution to the local water management.
\end{abstract}

\section{INTRODUCTION}

Eutrophication is the process in which the primary production of a water body increases with the contribution of organic matter and nutrients. As consequences, eutrophic waters have high degree of productivity and biomass at all trophic levels that produce quantitative and qualitative changes in the phytoplankton community and may lead to algae blooms Although there is no a unique formally defined threshold level, a population of algae must have a concentration of hundreds to thousands of cells per milliliter to be considered as a bloom (Wetzel, 2001).In order to assess the quality of water bodies, quantitative indicators are required to describe the frequency and the intensity of blooms. Chlorophyll-a concentration (chl-a) is widely used as an indicator of biomass and to characterize the trophic state of water body (Carlson, 1977). In the case of San Roque Reservoir, Córdoba, Argentina large amounts of nutrients, nitrogen and phosphorous species, lead to periodically and massive development of algae. As this water body is the most important source of water supply in the Province, the detection of blooms events is extremely important. Algal blooms are monitored in the lake solely by in situ measurements. However, during blooms events when the spatial distribution of phytoplankton biomass is high, conventional water sampling is not enough to characterize the distribution of the algae (Ferral et al., 2017). In this framework, remote sensing becomes an essential and effective tool to monitor algae bloom. In the passed decades, Landsat and MODIS program had been successfully used to monitor chlorophyll-a in San Roque reservoir (Germán et al., 2017b, Ferral et al., 2018, Alarcón et al., 2019). However, their lower spatial resolution (MODIS) and sparse acquisition (Landsat), disabled the joint extraction of spatial patterns and temporal trends. The Multispectral Instrument (MSI) on board of Sentinel 2 provides higher spatial (10 $\mathrm{m}$ in VIS and NIR bands), temporal (5 days at the equator in constellation) and spectral resolutions in comparison

\footnotetext{
*Corresponding author
}

to precedent Earth Observation (EO) programs (Ha et al., 2017, Tawfik et al., 2014). Therefore the expectation is that the extraction of eutrophic indicators will be improved accordingly. However, the spectral retrieval of [Chl-a] and algae species in turbid waters, using EO data, remains a challenge because of the presence of several optically active compounds like suspended sediment and colored dissolved organic matter, which increases the mixing rate of the water surface-reflectance (Ha et al., 2017) (Tyler et al., 2006) (Svab et al., 2005).

Unmixing methods appear as an option to overcome this issue (Jianguang et al., 2005). The aim of these algorithms is to identify constituent spectra, called endmembers, and a set of fractional abundances according to a predefined mixture model. The endmembers are generally assumed to represent the 'pure materials' in the image and the spectrum of each pixel is composed from their abundances (i.e. portion) (Keshava, Mustard, 2002). In the past decade, many unmixing algorithms to identify endmembers in a multi or hyperspectral images, have been developed. Most of them are based on the pure pixel assumption (i.e. the presence of at least one pure endmember in the data) and on linear mixture model. The latter adopts either a geometrical or a statistical framework (Parente, Plaza, 2010). Linear unmixing models are commonly used in the remote sensing community because of their light computational burden and clear conceptual meaning (Bioucas-Dias et al., 2012). Representative algorithms of this class are the pixel purity index (PPI) (Boardman, 1993), N-FINDR (Winter, 1999), and the vertex component analysis (VCA) (Nascimento, Dias, 2005). Several variations of them have been used for different applications, including water quality (Tyler et al., 2006), (Jianguang et al., 2005), (Alcântara et al., 2009), (Zhang et al., 2014) using single images that are representing the situation in specific dates. However, varying acquisition conditions, such as illumination or natural evolution of the scene, significantly alter the shape and the amplitude of the acquired spectral signatures. As consequence, the extracted endmembers are also changing 
between one image to another (Thouvenin et al., 2016) and do not allow the understanding of their evolution along time. In this work, we uses the multitemporal unmixing approach developed by (Thouvenin et al., 2016). It uses the perturbed linear mixing model (PLMM) (Thouvenin et al., 2015) on series of images acquired, over the same area at different time period, to resolve the spectral variability of the endmembers.

The main objective of our implementation is to characterize the spectral variability of San Roque reservoir during a long period of time using Sentinel 2 images. By applying the unmixing model, we would like to identify the optical components that create the leaving spectra of water and to estimate their abundance and their temporal distribution in the reservoir.

\section{MATERIAL AND METHODS}

\subsection{Study Area}

San Roque reservoir is situated at 600 meters over sea level in Punilla Valey, Córdoba Province, Argentina. Its shallow barycenter is in coordinates $31^{\circ} 22^{\prime} 56^{\prime \prime} \mathrm{S}, 64^{\circ} 27^{\prime} 56^{\prime \prime} \mathrm{W}$ (figure $1)$. The weather of the region is temperate with an annual average of approximately $720 \mathrm{~mm}$ (Rodríguez et al., 2006). Precipitation in the watershed has important annual variation (500 to $1000 \mathrm{~mm}$ ) (German et al., 2018) during two well distinct cycles; wet (from November to April) and dry (from May to October).

The drainage area of the Reservoir is about $1750 \mathrm{~km}^{2}$ with contribution of four tributaries: the San Antonio and Cosquín rivers and the Los Chorrillos and Las Mojarras streams . It has a single emissary, the Suquía River (Figure 1). These rivers and streams transport organic and inorganic material generated in the subbasins of the reservoir (Bustamente et al., 2007). Concerning the water column regime, the dam is considered monomictic (Morillo et al., 2002); this means that a convective mixing is happened once a year during the autumn and winter seasons. During the spring and the summer, a thermal stratification occurs, creating two separated water layers by a well-defined thermocline. In this period, anoxia episodes may also produced in the hipolimnion that provokes the release of high amounts of phosphates were adsorbed in the sediments(Ferral et al., 2017). Under these circumstances, in addition to light and warm temperature, algae are blooming. (Nicklisch et al., 2007). The temperature measured in the water varies from $12 \mathrm{C}$ to $18 \mathrm{C}$ in the cold season (April to September) and $20 \mathrm{C}$ to $25 \mathrm{C}$ in the warm season (October to March) (Germán et al., 2016). These well distinguished seasonal and yearly changes generate large variation in the water quality of the reservoir.

San Roque Reservoir is an eutrophic water body and this conditions lead to periodically and massive development of algae (Germán et al., 2016). As this water body is the most important source of water supply in the Province, the detection of blooms events is extremely important. Algal blooms are monitored in the lake by in situ measurements by the local government and they decided in October 2008, to install an artificial aeration system that breaks the thermal stratification and increases the oxygen level at the bottom of the lake, in order to mitigate the eutrophication process (see figure 1) (Ferral et al., 2017). In the basin, some low scale grazing can be found, but the main activities are human and they are concentrated in the urban areas of Carlos Paz (crossed by the San Antonio River) and La Falda (crossed by the Cosquín River) that have limited sewage treatment. During summer time, the population of these touristic cities are tripled. Nevertheless, during the dry season (winter, autumn and spring) large wild fires are common. These leave large burnt areas in the basin which eventually are ended as nutrients in the water of the lake (German et al., 2018).

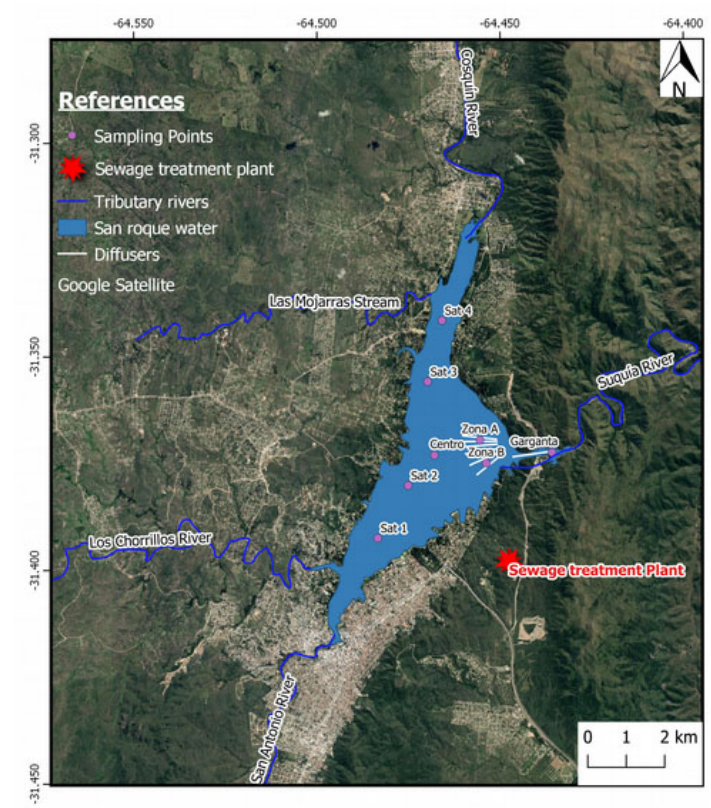

Figure 1. Map of San Roque reservoir and its monitoring stations and tributary rivers location.

\subsection{Satellite data}

All the available Sentinel 2 A B images covering the San Roque area were processed in this study. In total 125 images, with less than 30\% clouds cover, for the period August 2016 till August 2019, were automatically downloaded using the module i.sentinel.download available on GRASS GIS (GRASS Development Team, 2019). Further, the images were atmospherically corrected using the dedicated package Sen2cor (Louis et al., 2016), available as a standalone version. Although this algorithm was developed for land application, it was found suitable also for inland waters if land pixels are derived for the calculated parameters (Warren et al., 2019). Moreover, Sen2Cor gives comparable results to other atmospheric correction methods that were specifically developed for water applications (Main-Knorn et al., 2017). After the atmospheric correction, the water area of interest was cropped using a mask for land. This pre-processing scheme resulted in 125 images that were separated for each season with 34 images for the winter, 28 for the fall, 26 for the spring and 37 for the summer.

\subsection{Temporal Unmixing}

The selected unmixing model is conducted in three stages. In the first stage, the HySime (Hyperspectral signal subspace estimation) (Nascimento, Bioucas-Dias, 2007) is used to determinate the number of endmembers present in the image unsupersived. The method starts by estimating the signal and the noise correlation matrices and then selects the subset of the eigenvectors that best represents the signal subspace by the minimum mean squared error sense (Nascimento, Bioucas-Dias, 2007).

In the second stage, we used the open source algorithm 'Online unmixing of multitemporal hyperspectral images' proposed by (Thouvenin et al., 2016) to calculate the endmembers using 
the temporal series of the S2 images. This method assumes that number of pure pixels are present in the images and that the time series share these endmembers. Endmembers does not need to be present in each image but it has to be present in at least two images of the time series. The core temporal model, PLMM, consists on linear combination of the $\mathrm{R}$ endmembers affected by a perturbation vector accounting for temporal endmember variability. This variability is therefore essential and results from the evolution of the scene from one image to another(Thouvenin et al., 2016). In matrix form, the PLMM can be written as

$$
Y t=(M+d M t) A t+B t
$$

where $\mathrm{Yt}$ is an $\mathrm{L} \mathrm{N}$ matrix containing the pixels of the image, $\mathrm{M}$ denotes an $\mathrm{L} \mathrm{R}$ matrix containing the endmembers, At is an $\mathrm{R} \mathrm{N}$ matrix composed of the abundance vectors, $\mathrm{dMt}$ is an $\mathrm{L}$ $\mathrm{R}$ matrix whose columns are the perturbation vectors associated with the image and $\mathrm{Bt}$ is an $\mathrm{L} \mathrm{N}$ matrix accounting for the noise at time instant $t$. The non-negativity of sum-to-one constrain is considered to reflect the physical considerations.

Finally, the fully constraint least squares linear spectral unmixing (FCLSU) (Heinz et al., 2001) is used to calculate the abundances of each endmember. This algorithm minimizes the square error in the linear approximation of the image by imposing nonnegative and sum-to-one constraints for the abundances (Guerra et al., 2015).

\section{RESULTS AND DISCUSSION}

The temporal unmixing model resulted in the extraction of three endmembers for each season (Figure 2). The thick red line presents the seasonal spectra and the dashed blue line its contributing (dMt) vectors. As expected in turbid water, the spectra contain the absorption features of water as well as the optical properties of organic and inorganic materials. From spring to fall, the spectra of the turbid water (Endmember-1, Figure-2) is characterised by high reflectance in the wavelengths 550-665 $\mathrm{nm}$ (bands 2 to 4 of S2). The green pigment and the photosynthesis create by the algae are the origin of these spectral features. In the summer, when algae bloom is developed with the increase in temperature, this spectral peak is stretched toward the $700 \mathrm{~nm}$ (band 5). The spectra of these three seasons are also characterised by relatively high reflectance in the SWIR bands (i.e. 11 and 12) of S2, due to the contribution of sediments to the lake from the nearest tributaries. During the winter, with the decrease in temperature and inorganic nutrients, the spectral peak is centred in $550 \mathrm{~nm}$ and reduced toward the NIR. These observations are supported by the seasonal spectra of [Chl-a] (Endmember-2 in figure 2). From spring to fall, the photosynthetic algae (mainly of phyllum Cyanophyta which are flooded through the dam) produce green pigments and high reflectance in the red-bands of the NIR wavelengths (bands 4 to 7). Similar observation that highlights the spectral and spatial link between [Chl-a] and algae in water bodies was published by Guimaraes et al., in 2017 ((Guimarães et al., 2017)). In the winter, with the absent of algae due to the low temperatures, these spectral features cannot be observed.

Endmember- 3 in figure 2 is characterised by a very strong peak in bands 8 and $8 \mathrm{~A}$ during the spring and the summer time due to the presence of Ceratium hirundinella (brown algae) in the lake. During the winter, the presence of algae is diminished and the spectrum is distinguished by spectral slope from the NIR till the
SWIR wavelengths due to the contribution of sediments from the tributaries and the shores.

Figure 3 presents the proportion of each endmember in two S2 images from the 22/02/2017 and the 28/08/2018, using the summer and winter spectra, respectively. On the $22 / 02 / 2017$ a validation measurement campaign was conducted in the lake and water samples were collected. In this day, the lake was loaded with significant amount of sediments from the Cosquin river in the North and the Mojarras stream in the western part of the lake (dark blue in Abundance (1) in Figure 3). The [Chl-a] map (dark green in Abundance (2) in Figure 3) provides the limits of the spatial distribution of Microcystis sp (Cyanophyta) and Ceratium hirundinella. The latter (represented in Abundance (3)) developed in the center and the east side of the lake up to the Suquía river while the Microcystis sp (represented in Abundance (1)) developed at the center of the lake down to its southern shore. Laboratory algae analysis of water samples collected in four stations support this observation. In "Centro" and "Garganta" stations (see Figure 1), Ceratium hirundinella (brown algae) is dominant while in "Zona B" and "SAT 2" (see Figure 1) Microcystis sp (green algae) is more abundant (Germán et al., 2017a). These results are also supported by the summer spectra of the endmembers presented in figure 2 and the scientific work conducted by Zhao et. al. (Zhao et al., 2010). The spectrum of Ceratium (summer, endmember-3) is characterised with strong reduction in reflection beyond $700 \mathrm{~nm}$ (band 5 of S2) while Cyanophyta (summer, endmember-2) is characterised with second peak or high reflectance between 700 to $850 \mathrm{~nm}$ (bands 5 to 8 of S2) (Liew et al., 1999).

In the winter image of $28 / 08 / 2018$, the turbid water covers the entire lake (dark blue in Abundance (1) in Figure 3), [Chl-a] is sparse (light green in Abundance (2)) and the optical properties of floating sediments originated from the shores and tributary rivers, are detected (in red in Abundance (3)). Turbidity measured on this date, showed that in the entrance of the rivers turbidity was much higher (7.5 NTU San Antonio and 6.2 NTU Cosquín) than in the center (3.8 NTU Centro). These measures support the spatial distribution is observed in Abundance- 3 in Figure 3.

\section{CONCLUSIONS}

The scientific work presented in this paper highlights the importance of temporal-spectral analysis of turbid water in comparison to single date analysis. The dynamic of these types of water resulted in large daily spectral variation that diminished the efficiency of empirical model. However, temporal spectral analysis can resolve seasonal pattern and help in better understanding the inter-variation within the reservoir along the year. The presented result shown that the optical properties of turbid water were found all year around in San Roque reservoir. However, the presence of the algae varies from season to season and its spatial distribution can be directly linked to the distribution of Chl-a. This study concludes two-fold achievements; (1) it highlights the importance of the large temporal and spectral resolution of Sentinel 2 - MSI in understanding the dynamic of in-land aquatic processes and (2) it presents a methodological framework of seasonal spectral model for water reservoir. Future work should focus on the creation of seasonal empirical model of aquatic bio-chemical properties using the obtained seasonal spectra and the evaluation of different atmospheric correction algorithms for inland waters using more extensive in situ data. 
(1)
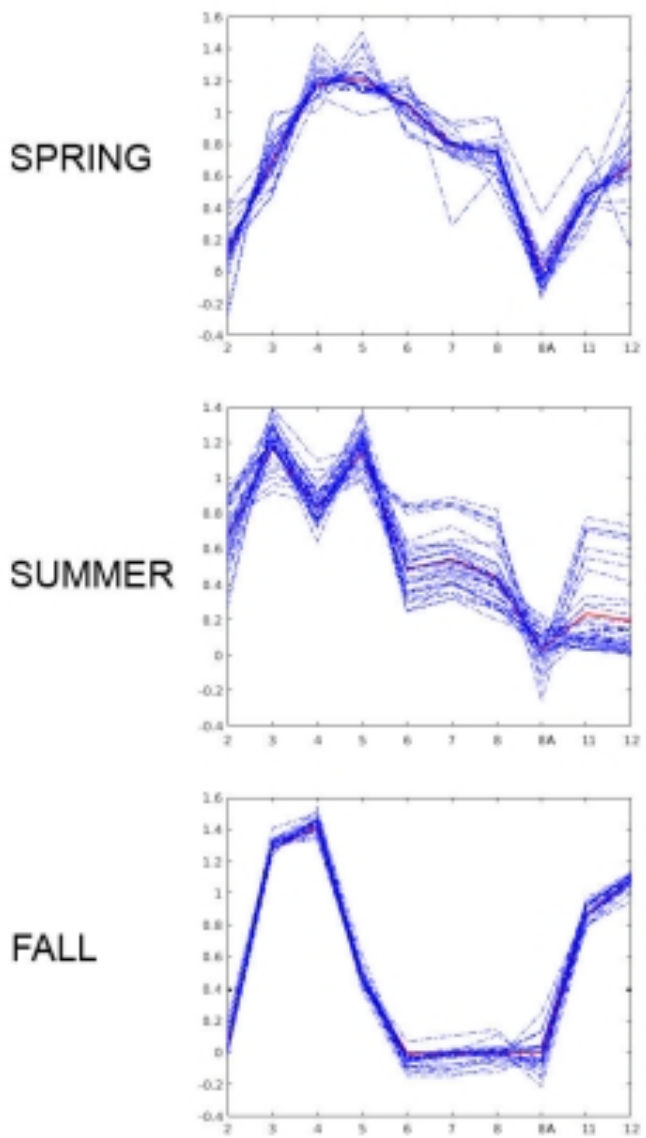

FALL

WINTER

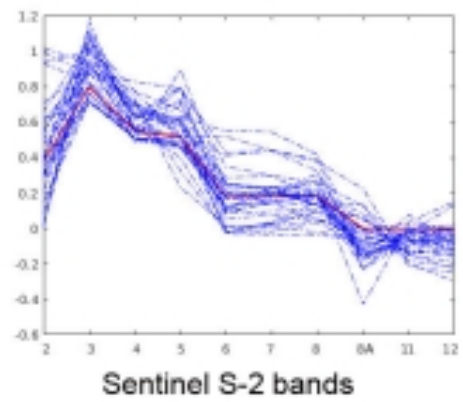

(2)
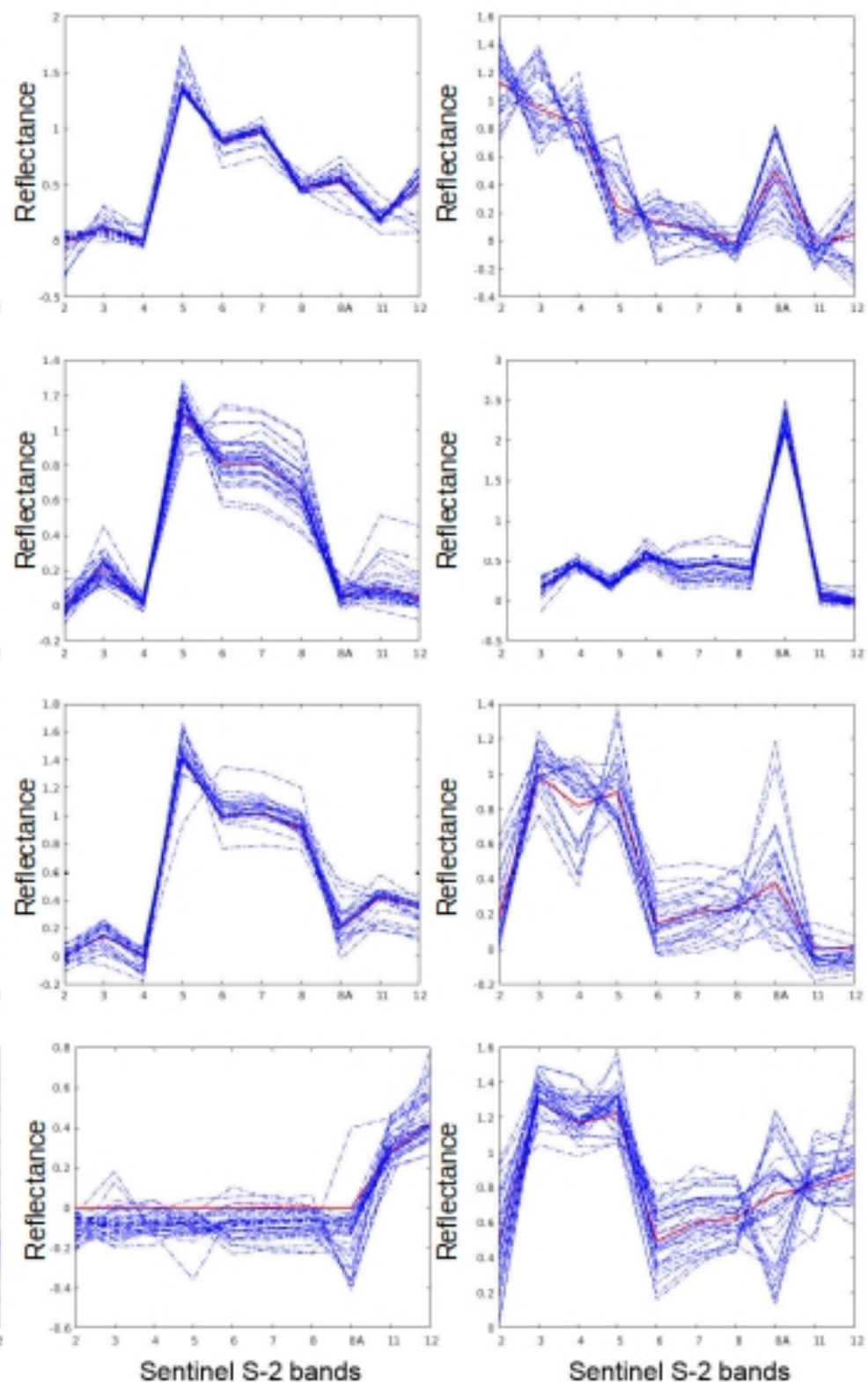

Figure 2. Multi-temporal Endmembers calculated for each season; in thick red line the seasonal endmember and in dashed blue line its perturbance $(\mathrm{dMt})$ vectors . 
(1)
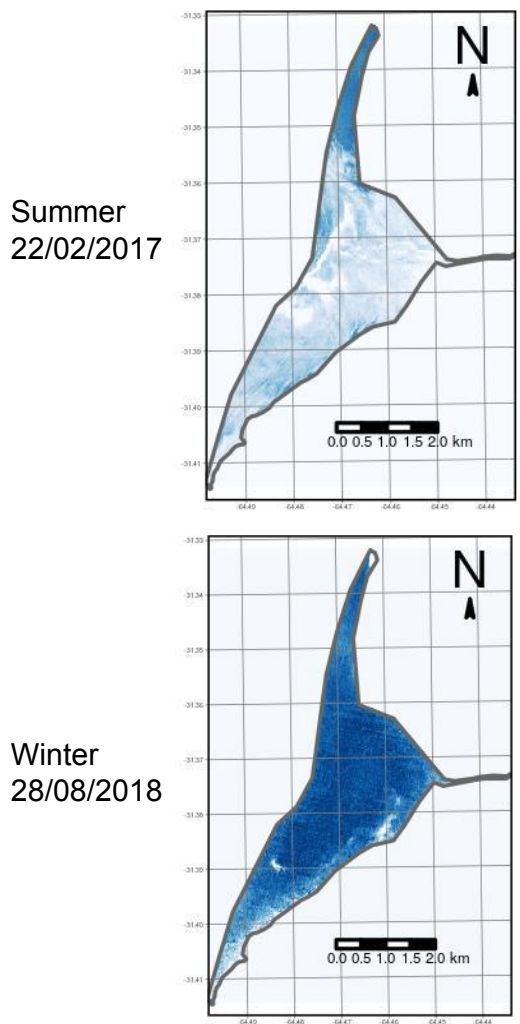

(2)
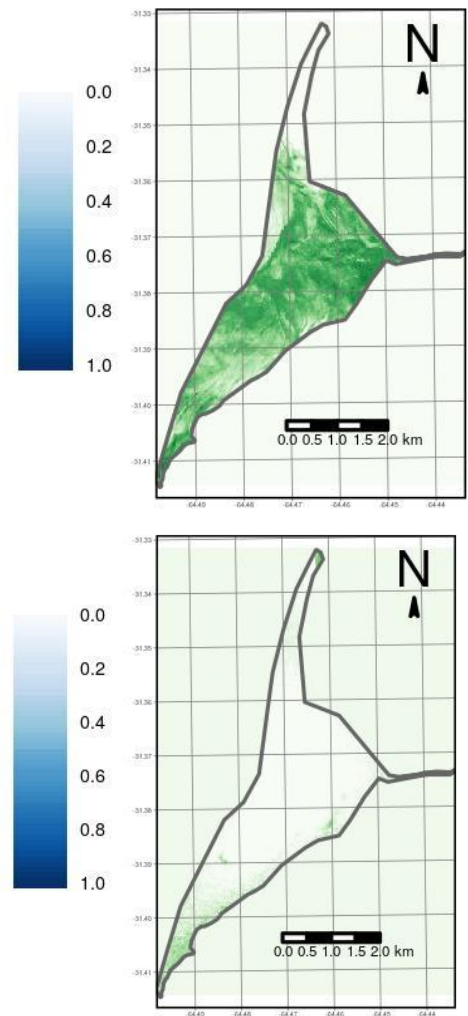

(3)
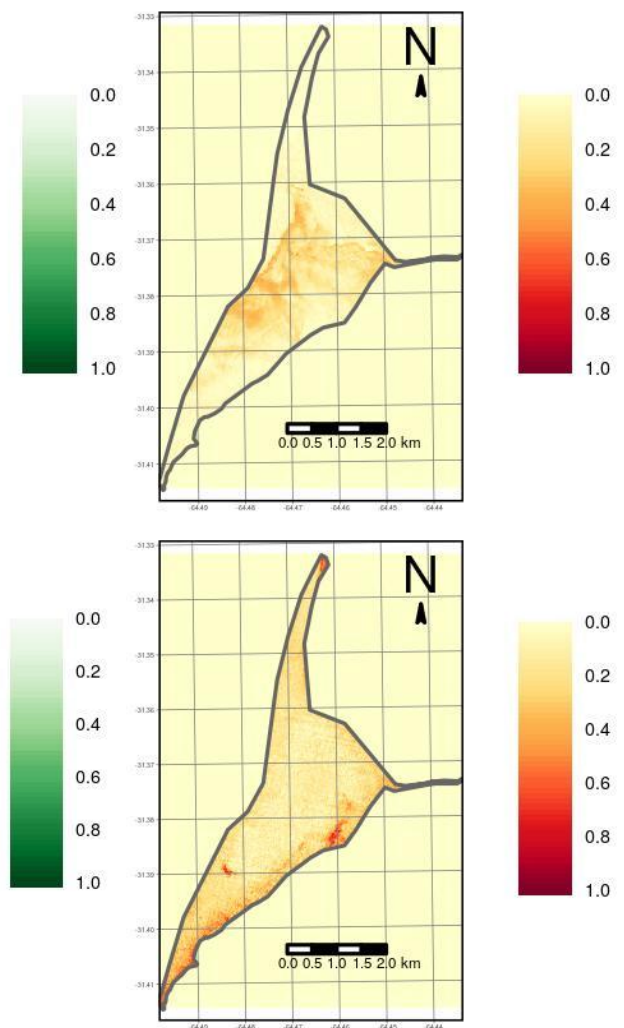

Figure 3. Abundances maps of temporal endmembers extracted using the summer and winter images of S2

\section{ACKNOWLEDGEMENTS}

This research is conducted in the framework of EOXPOSURE project under grant agreement No 734541 of the Horizon 2020 research and innovation program (http://www.h2020eoxposure.eu/). Special thanks to Antonio Plaza, Javier Plaza and Mario Haut of the HyperComp lab in Extremadura University, for their valuable contributions.

\section{REFERENCES}

Alarcón, A. G., German, A., Aleksinkó, A., Ferreyra, M. F. G., Scavuzzo, C. M., Ferral, A., 2019. Spatial algal bloom characterization by landsat 8-oli and field data analysis. IGARSS 2018-2018 IEEE International Geoscience and Remote Sensing Symposium, IEEE.

Alcântara, E., Barbosa, C., Stech, J., Novo, E., Shimabukuro, Y., 2009. Improving the spectral unmixing algorithm to map water turbidity distributions. Environmental Modelling \& Software, 24(9), 1051-1061.

Bioucas-Dias, J. M., Plaza, A., Dobigeon, N., Parente, M., Du, Q., Gader, P., Chanussot, J., 2012. Hyperspectral unmixing overview: Geometrical, statistical, and sparse regression-based approaches. IEEE journal of selected topics in applied earth observations and remote sensing, 5(2), 354-379.

Boardman, J. W., 1993. Automating spectral unmixing of AVIRIS data using convex geometry concepts.

Bustamente, M. A., Ruibal Conti, A. L., Rodriguez, M. I., Lopez, F., Busso, F., Bonetto, C., 2007. Caracterización del régimen trófico del embalse san roque, córdoba.). XXI Congreso Nacional del Agua. Tucumán.

Carlson, R. E., 1977. A trophic state index for lakes1. Limnology and oceanography, 22(2), 361-369.

Ferral, A., Solis, V., Frery, A., Aleksinko, A., Bernasconi, I., marcelo Scavuzzo, C. et al., 2018. In-situ and satellite monitoring of the water quality of a eutrophic lake intervened with a system of artificial aireation. IEEE Latin America Transactions, 16(2), 627-633.

Ferral, A., Solis, V., Frery, A., Orueta, A., Bernasconi, I., Bresciano, J., Scavuzzo, C. M., 2017. Spatio-temporal changes in water quality in an eutrophic lake with artificial aeration. Journal of water and land development, 35(1), 27-40.

German, A., Argañaraz, J., Lighezzolo, A., Ferral, A., 2018. Remote sensing of water quality in a watershed and its relationship with wildfires, precipitation and urban growth. 2018 IEEE Biennial Congress of Argentina (ARGENCON), IEEE, 1-7.

Germán, A., Ferral, A., Scavuzzo, M. C., Guachalla Alarcon, A., Tropper, I., Ibañez, G., Torrusio, S., Shimoni, M., 2017a. Spectral monitoring of algal blooms in an eutrophic lake using sentinel-2. Geoscience and Remote Sensing Symposium (IGARSS), 201 IEEE International, IEEE, 4008-4011.

Germán, A., Tauro, C., Andreo, V., Bernasconi, I., Ferral, A., 2016. Análisis de una serie temporal de clorofila-a a partir de imágenes modis de un embalse eutrófico. Biennial Congress of Argentina (ARGENCON), 2016 IEEE, IEEE, 1-6. 
Germán, A., Tauro, C., Scavuzzo, M. C., Ferral, A., 2017b. Detection of algal blooms in a eutrophic reservoir based on chlorophyll-a time series data from modis. Geoscience and Remote Sensing Symposium (IGARSS), 2017 IEEE International, IEEE, 4008-4011.

GRASS Development Team, 2019. Geographic Resources Analysis Support System (GRASS GIS) Software. Open Source Geospatial Foundation, USA.

Guerra, R., Santos, L., López, S., Sarmiento, R., 2015. A new fast algorithm for linearly unmixing hyperspectral images. IEEE Transactions on Geoscience and Remote Sensing, 53(12), 6752-6765.

Guimarães, T., Veronez, M., Koste, E., Gonzaga, L., Bordin, F., Inocencio, L., Larocca, A., de Oliveira, M., Vitti, D., Mauad, F., 2017. An Alternative Method of Spatial Autocorrelation for Chlorophyll Detection in Water Bodies Using Remote Sensing. Sustainability, 9(3), 416.

Ha, N. T. T., Thao, N. T. P., Koike, K., Nhuan, M. T., 2017. Selecting the Best Band Ratio to Estimate Chlorophyll-a Concentration in a Tropical Freshwater Lake Using Sentinel 2A Images from a Case Study of Lake Ba Be (Northern Vietnam). ISPRS International Journal of Geo-Information, 6(9), 290.

Heinz, D. C. et al., 2001. Fully constrained least squares linear spectral mixture analysis method for material quantification in hyperspectral imagery. IEEE transactions on geoscience and remote sensing, 39(3), 529-545.

Jianguang, W., Qing, X., Qinhuo, L., Yi, Z., 2005. Extraction of chlorophyll-a concentration based on spectral unmixing model using field hyperspectral data in taihu lake. Technical report, CHINESE ACADEMY OF SCIENCES BEIJING INST OF REMOTE SENSING APPLICATIONS.

Keshava, N., Mustard, J. F., 2002. Spectral unmixing. IEEE signal processing magazine, 19(1), 44-57.

Liew, S. C., Lin, I., Kwoh, L. K., Holmes, M., Teo, S., Gin, K., Lim, H., 1999. Spectral reflectance signatures of case ii waters: potential for tropical algal bloom monitoring using satellite ocean color sensors. SEMINAR ON MARINE AND FISHERIES SCIENCES, 10, 1-8.

Louis, J., Debaecker, V., Pflug, B., Main-Knorn, M., Bieniarz, J., Mueller-Wilm, U., Cadau, E., Gascon, F., 2016. Sentinel2 sen2cor: L2a processor for users. Proceedings of the Living Planet Symposium, Prague, Czech Republic, 9-13.

Main-Knorn, M., Pflug, B., Louis, J., Debaecker, V., MüllerWilm, U., Gascon, F., 2017. Sen2cor for sentinel-2. Image and Signal Processing for Remote Sensing XXIII, 10427, International Society for Optics and Photonics, 1042704.

Morillo, S., Dasso, C., Bustamante, M., Granero, M., López, F., 2002. Modelación unidimensional de la limnología física del embalse san roque, córdoba, argentina. XIX Congreso Nacional del Agua.

Nascimento, J. M., Bioucas-Dias, J. M., 2007. Hyperspectral signal subspace estimation. 2007 IEEE International Geoscience and Remote Sensing Symposium, IEEE, 32253228.
Nascimento, J. M., Dias, J. M., 2005. Vertex component analysis: A fast algorithm to unmix hyperspectral data. IEEE transactions on Geoscience and Remote Sensing, 43(4), 898-910.

Nicklisch, A., Shatwell, T., Köhler, J., 2007. Analysis and modelling of the interactive effects of temperature and light on phytoplankton growth and relevance for the spring bloom. Journal of Plankton Research, 30(1), 75-91.

Parente, M., Plaza, A., 2010. Survey of geometric and statistical unmixing algorithms for hyperspectral images. 2010 2nd Workshop on Hyperspectral Image and Signal Processing: Evolution in Remote Sensing, IEEE, 1-4.

Rodríguez, M. I., Ruiz, M., Vilchez, G., Crema, N., Ruibal Conti, A., Bustamante, M., Angelaccio, C., Busso, F., Bonfanti, E., López, F., 2006. Monitoreo integral de un cuerpo de agua eutrofico embalse san roque (cordoba, argentina). I Congreso Internacional sobre Gestión y Tratamiento Integral del Agua.

Svab, E., Tyler, A., Preston, T., Presing, M., Balogh, K., 2005. Characterizing the spectral reflectance of algae in lake waters with high suspended sediment concentrations. International Journal of Remote Sensing, 26(5), 919-928.

Tawfik, M., Farag, H., Salama, M., 2014. Sentinel-2 red-edge bands capabilities on retrieving Chlorophyll-a in turbid water: case study: Lake Burullus, Egypt.

Thouvenin, P.-A., Dobigeon, N., Tourneret, J.-Y., 2015. Hyperspectral unmixing with spectral variability using a perturbed linear mixing model. IEEE Transactions on Signal Processing, 64(2), 525-538.

Thouvenin, P.-A., Dobigeon, N., Tourneret, J.-Y., 2016. Online unmixing of multitemporal hyperspectral images accounting for spectral variability. IEEE Transactions on Image Processing, 25(9), 3979-3990.

Tyler, A., Svab, E., Preston, T., Présing, M., Kovács, W., 2006. Remote sensing of the water quality of shallow lakes: A mixture modelling approach to quantifying phytoplankton in water characterized by high-suspended sediment. International Journal of Remote Sensing, 27(8), 1521-1537.

Warren, M. A., Simis, S. G., Martinez-Vicente, V., Poser, K., Bresciani, M., Alikas, K., Spyrakos, E., Giardino, C., Ansper, A., 2019. Assessment of atmospheric correction algorithms for the Sentinel-2A MultiSpectral Imager over coastal and inland waters. Remote sensing of environment, 225, 267-289.

Wetzel, R. G., 2001. Limnology: lake and river ecosystems. Gulf Professional Publishing.

Winter, M. E., 1999. N-findr: An algorithm for fast autonomous spectral end-member determination in hyperspectral data. Imaging Spectrometry $V, 3753$, International Society for Optics and Photonics, 266-275.

Zhang, Y., Ma, R., Duan, H., Loiselle, S., Xu, J., 2014. A spectral decomposition algorithm for estimating chlorophyll-a concentrations in Lake Taihu, China. remote Sensing, 6(6), 50905106.

Zhao, D., Xing, X., Liu, Y., Yang, J., Wang, L., 2010. The relation of chlorophyll-a concentration with the reflectance peak near $700 \mathrm{~nm}$ in algae-dominated waters and sensitivity of fluorescence algorithms for detecting algal bloom. International Journal of Remote Sensing, 31(1), 39-48. 